\title{
Sources and level of information about health issues and preventive services among young-old persons in Switzerland
}

\author{
Laurence Seematter-Bagnoud, Brigitte Santos-Eggimann \\ Health Services Research, Institute of Social and Preventive Medicine (IUMSP), Centre Hospitalier Universitaire Vaudois and University of \\ Lausanne, Lausanne, Switzerland
}

Submitted: 4 July 2006, Revised: 20 March 2007, Accepted: 29 March 2007

\section{Summary}

Objectives: to describe the sources of health information in young-old persons, and how they feel informed about preventive services.

Methods: 1,567 randomly selected persons aged 65-69 years were asked where they did get information about health, and whether they felt sufficiently informed about recommended preventive services.

Results: Most participants (over $90 \%$ ) cited their physician as a source of health information, while only $4 \%$ cited the Internet. Level of information was low for several preventive services, including colon cancer screening ( $55 \%$ felt sufficiently informed) and immunization against pneumonia (27\% sufficiently informed).

Conclusions: Promotion of preventive services in older populations should take into account the preponderant role of physicians as a source of information and advice.

Key words: Aged - Preventive health services - Information systems - Knowledge.

The baby-boom generation is reaching the age of retirement in Switzerland as in other European countries. Consequently, the segment of the population comprising people aged between 60-65 years and 75-80 years, the so-called young-old persons, is expected to grow massively in the next decades. Although most young-old persons are in relatively good health, they face a high risk of chronic diseases and cancer, some of which are preventable. Delivery of preventive and screening services is therefore important in this age category, but previous studies have reported a low level of preventive services uptake (Birchmeier et al. 2002; Blozik et al. 2007; Peter-Wuest et al. 2000). In this context, assessing the level of information of young retirees about recommended preventive services is important to define health education and health promotion strategies.

Besides investigating which preventive services are less familiar to young-old persons, knowing where they get healthrelated information is essential to develop strategies aiming at increasing access to prevention in later life. The way older persons inform themselves on health issues has not been widely investigated, except in a few studies on specific diseases, such as cancer (Basch et al. 2004). Physicians are a traditional source of information about health, and probably continue to play a major role in the older population. However, the Internet is assumed to be used by an increasing proportion of individuals reaching the old age.

The objectives of this analysis were to examine which sources of health information were used by young-old persons and their self-reported level of information about specific preventive services.

\section{Methods}

In Spring 2004, 3,056 community-living residents of Lausanne born in 1934-38 were randomly sampled using the population registry. These persons were contacted by mail to participate in a cohort study on age-related frailty (Santos-Eggimann 2005). Baseline data were collected in 2004 on 1,567 persons using a postal questionnaire about different aspects of health (physical, mental, social), as well as about significant events throughout their life course. In order to create the Lausanne Cohort Lc65+, baseline data collection was completed in 2005 with a face-to-face interview, a physical examination, as well as with tests of physical and mental performances. 
Table 1 Source of health information, by gender

\begin{tabular}{llll}
\hline Source & Women (\%) & Men (\%) & P value \\
\hline Physician & 88.0 & 87.3 & .119 \\
Relatives & 32.9 & 33.9 & .271 \\
Newspapers & 28.7 & 27.4 & .207 \\
TV, Radio & 28.3 & 23.5 & .020 \\
Home care services & 7.2 & 3.7 & .003 \\
Internet & 3.0 & 5.7 & .010 \\
\hline
\end{tabular}

The initial postal questionnaire also asked participants where they searched for information about health (physicians, relatives, medias, Internet, home help agencies, others), and whether they felt sufficiently informed about specific preventive services.

This work firstly investigates the pattern of utilization of sources of health information by gender, and then describes the proportion of participants reporting sufficient knowledge about preventive services, again with a gender comparison. For bivariate analyses, participants who mentioned only physicians as a source of health information were compared to all other participants, using chi-squared tests. Variables significantly associated with the use of physicians as unique source of information were then included in a multivariable logistic regression model.

\section{Results}

A majority of participants were women $(58.7 \%)$, and most were born in Switzerland (77.2\%). There was no statistical difference in the gender of participants and non-participants $(\mathrm{p}=.934)$, nor in the distribution of their years of birth (men: $p=.271$, women: $p=.600$ ). Data extracted from the 2000 Federal Census and the 31.12.2004 population registry were also used to compare study participants to the original sample frame of Lausanne residents registered in the same age category. The comparison showed that the participants were highly representative regarding all variables available (gender, year of birth, nationality, marital status, proportion living alone, and current professional activity), except for the level of achieved education: the proportion of persons having completed university was slightly higher, but this difference might result from the presence of missing data (16.2\%) in the Federal Census, while missing education was less than $1 \%$ in the study. About two-thirds $(62.5 \%)$ of the participants rated their health as good or very good. Most reported one or more chronic conditions $(86.9 \%)$, and had at least one medical visit during the previous year $(92.5 \%)$.

A large majority of men and women $(87.8 \%)$ would turn to physicians in case they would need information about health issues. Then, relatives were reported by about a third (32.9\%). While $28.1 \%$ of participants cited the television and radio as sources of health information, only $4.2 \%$ reported using the Internet to this purpose.

Table 1 displays self-reported sources of information in men and women. Although the gender comparison shows few significant differences, women tended to use more frequently each possible source of information, except the Internet.

About $40 \%$ of the participants relied exclusively on physicians as a source of health information. As shown in Table 1, these participants were more frequently born outside Switzerland, had a lower education, a worst self-reported health, and a higher number of physician visits. In multivariate analysis, using no other source of health information than physicians was associated to being born outside Switzerland and to a lower level of achieved education. A borderline association was found with a higher number of physician visits during the last year.

Most participants felt sufficiently informed about influenza vaccination $(94.6 \%)$. By contrast, only one in four participants reported sufficient information concerning immunization against pneumonia (26.6\%). Among cancer screening interventions, colon cancer was the item for which participants felt less frequently informed (men: $50.7 \%$, women: $58.5 \%$ ). Most women were satisfied with their knowledge regarding screening for gynaecologic cancers (breast: $96.8 \%$, cervix: $92.3 \%$ ), while $71.1 \%$ of men felt informed about screening for prostate cancer. Again, although the difference did not always reach statistical significance, gender comparisons showed that women more frequently reported a sufficient level of information for all preventive measures (data not shown).

\section{Discussion}

Our results emphasize the role of physicians as the preponderant source of health information for most young-old persons. Lower education seems to be the major factor associated with relying on physicians as unique source of health information. Being born outside Switzerland was also associated with reporting no other source. Searching for information by physicians might be related to cultural beliefs, or to difficulties in understanding the information given in the medias. Newspapers, television and radio were however cited by about one in four persons as a source of health information, which confirms their role in conveying preventive messages.

In spite of the belief that the Internet is increasingly used among young-old persons, a very low proportion of participants exploited it to get health information. In another Swiss study, $10 \%$ of primary care patients reported using the Internet to get medical information, and the proportion decreased 
Table 2 Comparison of participants according to the use of physician as unique source of information and adjusted odds ratios

\begin{tabular}{|c|c|c|c|c|c|c|}
\hline & $\begin{array}{l}\text { Physician only } \\
(\mathrm{N}=610, \%)\end{array}$ & $\begin{array}{l}\text { Other source also } \\
(\mathrm{N}=913, \%)\end{array}$ & $\begin{array}{l}\text { P-value } \\
\text { (from bivariate } \\
\text { analyses) }\end{array}$ & $\begin{array}{l}\text { Adjusted Odds } \\
\text { ratio }^{{ }^{a}}\end{array}$ & $95 \% \mathrm{Cl}^{\mathrm{a}}$ & P-value a \\
\hline Women & 56.7 & 59.5 & .286 & - & - & - \\
\hline $\begin{array}{l}\text { Low education } \\
\text { (apprenticeship, obligatory } \\
\text { school or none) }\end{array}$ & 73.7 & 60.9 & $<.001$ & 1.893 & $1.50-2.40$ & 0.000 \\
\hline Living alone & 34.2 & 36.0 & .469 & - & - & - \\
\hline Born outside Switzerland & 31.3 & 25.2 & .006 & 1.403 & $1.10-1.78$ & 0.006 \\
\hline Poor/fair self-rated health & 40.6 & 35.0 & .026 & 1.040 & $0.82-1.32$ & 0.748 \\
\hline $\begin{array}{l}\text { Comorbidity (4+ chronic } \\
\text { diseases) }\end{array}$ & 23.2 & 22.3 & .658 & - & - & - \\
\hline $\begin{array}{l}\text { Number of physician visits } \\
\text { above the median } \\
\text { (4+ last } 12 \text { months) }\end{array}$ & 58.5 & 53.2 & .05 & 1.240 & $0.99-1.56$ & 0.065 \\
\hline
\end{tabular}

${ }^{\text {a }}$ Adjusted odds ratios ( $95 \% \mathrm{Cl}$ and P-value) from logistic regression model, including education, place of birth, self-rated health, and number of physician visits (excluding variables not significantly associated in bivariate analyses).

to $1 \%$ among those aged 65 years and older (Jeannot et al. 2004). The higher proportion of $4 \%$ in this sample might be explained by the urban setting in which the study took place, and the population constituted of young-old persons exclusively. As reported in a recent study (Seniorwatch 2002) on the familiarity of communication technologies among older people, use of the Internet decreases sharply with age. This work showed that $12.8 \%$ of people aged $60-69$ years in Europe were regular Internet users, but did not report about the purposes of Internet use in this population. Another recent study in Sweden showed that the proportion of people using the Internet to retrieve health information did double between year 2000 and year 2005, among younger adults as well as among middle-aged ones, and achieved $20 \%$ in persons aged 50 to 64 years in 2006 (Rahmqvist \& Bara 2006). The use of the Internet will probably increase regularly during the next decades, but it seems to be currently strongly related to having a professional occupation. A higher proportion of men quoting this source of information in our data and the drop in use with age reported in other studies support this hypothesis.

Women more frequently reported several sources of health information. They also more often reported sufficient knowledge about preventive measures. These findings are in accordance with previous studies. Women usually show more interest in health subjects than men and want to get more information (Beier et al. 2003; Stewart et al. 2004), which is probably related to their social role of caregivers.

Self-reported knowledge varied widely across the different screening and preventive services, from most persons reporting sufficient knowledge about influenza vaccination to most feeling insufficiently informed when pneumococcus vaccine was concerned. A limitation to the interpretation of these re- sults is that they are based on self-report, and do not necessarily reflect true knowledge of participants. However, subjective assessment regarding health matters should not be discarded, as subjective health is correlated with risk of death (SinghManoux et al. 2007). Interestingly, the pattern of knowledge about recommended preventive services is quite consistent with the pattern of delivery of these interventions in Swiss older persons. Indeed, a study did show a very low prevalence of immunization against pneumococcus compared to influenza (Birchmeier et al. 2002), and older Swiss women participating in the Survey of Health, Aging and Retirement in Europe also reported a higher use of mammography as compared to colonoscopy or fecal occult blood testing ${ }^{1}$. A sensible interpretation of our data is that there is a real lack of information among those persons who report being insufficiently informed, while we cannot really assess the level of knowledge among those reporting having sufficient information.

As physicians represent the preponderant source of information, their central role must be recognized. Previous work indicated that physician advice and support are the main factors increasing uptake of preventive care (Yanovitzky \& Blitz 2000). Physicians may not be aware of this role, or face several barriers, such as lack of time or insufficient training (Hudon et al. 2004). The traditional role of physicians is probably more oriented towards curing than preventing, and most physician visits are devoted to the current health problem of the patient, allowing little time to address prevention. Gynaecologists are a special case, because part of their work consists in gynaecological check-ups, with cancer screening. In Switzerland, a high proportion of women are used to plan

\footnotetext{
${ }^{1}$ Peytremann-Bridevaux I, personal communication, March 2007
} 
regular gynaecological check-ups, and this is consistent with a large majority of women reporting sufficient information about screening for gynaecological cancers. In Germany, where gynaecological check-ups are reimbursed by the statutory health insurance, more than $80 \%$ of women report having received information about gynaecological screening by gynaecologists (Klug et al. 2005).

Another factor that might discourage physicians of recommending preventive services is the cost imputed to the patient. In this context, it is worth noting that immunization against pneumococcus is not reimbursed by the social health insurance in Switzerland, as opposed to influenza vaccination. Finally, even though most older persons rely on physicians to get health information, better knowledge on some preventive issues might reflect more extensive reporting in the medias.
Notably, there are national campaigns supporting influenza vaccination, and several Cantons have implemented breast cancer screening programmes with systematic mailing of invitations to participate.

In conclusion, promotion of preventive services in older populations should take into account the preponderant role of physicians as a source of information and advice, particularly for subgroups with unfavourable socio-economic profile, and offer training and support for advising about and delivering preventive care.

\section{Acknowledgements}

The authors wish to thank the study participants, and are grateful to the City of Lausanne and to the Service de la Santé Publique du Canton de Vaud for funding this project.

\section{References}

Basch EM, Thaler HT, Shi W, Yakren S, Schrag D (2004). Use of information resources by patients with cancer and their companions. Cancer 100 2476-83.

Beier ME, Ackerman PL (2003). Determinants of health knowledge: an investigation of age, gender, abilities, personality and interests. J Pers Soc Psychol 84: 439-48.

Birchmeier M, Favrat B, Pécoud A et al (2002). Improving influenza vaccination rates in elderly. J Fam Pract 51: 856.

Blozik E, Meyer K, Simmet A, Gillmann G, Bass AA, Stuck AE (2007). Gesundheitsförderung und Prävention im Alter in der Schweiz. Ergebnisse aus dem Gesundheitsprofil-Projekt. Schweizerisches Gesundheitsobservatorium, Neuchâtel. Arbeitsdokument $N^{\circ} 21$.

Hudon E, Beaulieu M-D, Roberge D (2004). Integration of the recommendations of the Canadian Task Force on Preventive Health care. Obstacles perceived by a group of family physicians. Fam Pract 21: 11-7.

Jeannot JG, Froehlich F, Wietlisbach V, Burnand $B$, Terraz O, Vader JP (2004). Patient use of the Internet for health care information in Switzerland. Swiss Med Wkly 134: 307-12.
Klug S, Hetzer M, Blettner M (2005). Screening for breast and cervical cancer in a large German city: participation, motivation and knowledge of risk factors. Eur J Public Health 15: 70-7.

Peter-Wuest I, Stuck AE, Dapp U et al (2000). Präventive Hausbesuche im Alter: Entwicklung und Pilottestung eines multidimensionalen Abklärungsintruments. Z Gerontol Geriatr 33: 44-51.

Rahmqvist M, Bara AC (2006). Patients retrieving information via the Internet: a trend analysis of a Swedish population, 2000-2005. Poster, Conference of the European Public Health Association, Montreux.

Santos-Eggimann B (2005). Maladies cardiovasculaires et indicateurs de fragilité lors du recrutement de la lère vague de la cohorte LC65+. Rapport au Service de la Santé Publique du canton de Vaud. Institut de Médecine Sociale et Préventive, Lausanne, avril 2005. Available on www.iumsp.ch, Unité des Services de Santé.

SeniorWatch (2002). Older people and information society technology. A global analysis. Available on www.seniorwatch.de.

Singh-Manoux A, Guegen A, Martikainen P, Ferrie J, Marmot M, Shipley M (2007). Self-rated health and mortality: short-and long-term associations in the Whitehall II Study. Psychosom Med 69: 138-43.
Stewart DE, Abbey SE, Shnek ZM, Irvine J, Grace SL (2004). Gender differences in health information needs and decisional preferences in patients recovering from an acute ischemic coronary event. Psychosom Med 66: 42-8.

Yanovitzky I, Blitz CL (2000). Effect of media coverage and physician advice on utilization of breast cancer screening by women 40 years and older. J Health Comm 5: 117-34.
To access this journal online: http://www.birkhauser.ch/IJPH 